\title{
The ethics of general practice and advertising
}

\author{
Richard D Colman York
}

\section{Author's abstract}

UK general practitioners (GPs) are self-employed entrepreneurs running small businesses with commercial considerations. In this situation there is no clear distinction between information, self-promotion and advertising. In response to the growing public demand for more information about medical services, the medical profession should voluntarily accept the notion of soft self-promotion in the form of 'notices' or 'announcements' placed in newspapers. Newspapers are the most effective way of giving easy access to information. The resistance to newspapers may be more concerned with preserving certain medical traditions than consideration of the public interest. The General Medical Council's (GMC's) arguments against soft self-promotion are seen as misguided paternalism, inconsistent and irrational.

A rational debate about the ethics of 'advertising' by doctors is difficult without first drawing up definitions and boundaries within which to limit the discussion. For this paper I will be concerned only with UK medical practice and with doctors who are specifically trained and thereby eligible to be general practice principals, this being my area of concern and experience.

According to the GMC guidelines (1), the dissemination of information about the services a doctor is prepared to provide is of benefit to the public and is to be encouraged, whereas advertising is not. In the first part of this paper I will try to determine, in the medical context, the differences, if any, between supplying information and advertising.

To focus on the issues I will first use the British Medical Association's (BMA's) ethical committee's definition of what is the difference. This states that 'advertising is for the commercial benefit of the doctor concerned' (2).

This definition pinpoints an aspect of the problem. 'Advertising', in medical circles, is an emotionally charged word strongly suggestive of information of a promotional nature for commercial gain. It is therefore

\section{Key words}

Announcements; advertising; newspapers; paternalism; liberty. an unsatisfactory term to use for those wishing to emphasise the legitimate informational content of the message. A much more satisfactory term with less promotional and commercial connotations, would be the concept of the placing of a 'Notice' as in 'Public Notice' or of an 'announcement' rather than advertisement.

It is the use of notices or anouncements for the promoting of personal financial gain which is considered to be unethical. Certainly most would agree that the information content should be regulated and should not contain or imply value judgements such as claims that someone was a special authority, or much experienced, world famous or other such puffery likely to mislead the public. But all information about the availability of services contains some element of promotion. As long as GPs are self-employed and paid on a per-capita basis as well as for items of service, a GP's income will increase by attracting more patients. Special interest clinics within the practice such as Wellwomen clinics will pay handsomely through item-ofservice payments for providing screening and contraceptive services, the inserting of only one IUCD paying $£ 42.75$.

It could be said that the motive for such special clinics and auxiliary services is for the provision of good health care but if it was also predictable that they would be financially rewarding then there may be a possible commercial motive as well. The popularity and wide GP readership of the journal Medeconomics, which specialises in informing GPs how to obtain the maximum income out of their practice, suggests that commercial motives operate in general medical practice. As long as GPs are self-employed and seen to be running small businesses these will function to some degree as commercial organisations and all information relating to the practice is likely to have some promotional content and be of commercial benefit.

Such information could therefore be classified as advertising under the BMA's definition. However, both the BMA and the GMC find acceptable for public distribution, information which includes doctors' names, addresses, telephone numbers, consulting arrangements and appointment systems, procedures for emergencies, times and arrangements of special clinics and auxiliary services as well as other facilities 
available to the general public (3). Paragraph 93 of the GMC guidelines in fact encourages the distribution of this information, stating that in order to make an informed choice of general practitioner, prospective patients need to have ready access to accurate, comprehensive and well presented information about the doctors practising in their area. Lists of such practitioners, including factual information about the practitioners and their qualifications, the facilities available and practice arrangements in each case should be distributed widely for the benefit of members of the public, making full use of public libraries, community health councils and other centres of local information'. (Local information centres are limited to Citizens' Advice Bureaux and Family Practitioner Committees: personal communication from the President of the GMC, through a Mr A R C Kershaw in reply to a letter I sent to the GMC 1987 Jan 9.)

Thus for the GMC it is not just the content of information but the manner and site of its distribution which is important in deciding whether it is or is not advertising. The use of newspapers to disseminate acceptable information is considered to be advertising and unethical. Yet the use of newspapers is perfectly acceptable in other countries such as Germany, Finland, Japan, Denmark, Italy, Ireland, Australia, Sweden and the USA.

The advantages of newspapers are that they are widely distributed and the information they contain is likely to be up to date at the time of printing. Changes of address, telephone numbers, new partners or facilities can be notified to the public immediately, cheaply and efficiently. There would be no need for expensive reprinting of practice leaflets which would have to be sent or taken to individual information centres and out-of-date ones retrieved. There would be no need for staff to check continually that centres still have the updated information which is at present necessary.

In the High Court the GMC could not explain the reasons for their specific opposition to the use of newspapers (4). However, some people may see newspapers as the thin edge of the wedge, as the first step to neon lights and expensive TV commercials, opening up the way for the commercialisation of the profession. Whilst some see commercialisation as a way of improving the performance and efficiency of medical services by injecting a sense of competition, others see the possibility of the public being seduced by progressively more promotional and alluring announcements into having expensive but unnecessary medical treatment. Unfortunately even within the NHS, which is free of advertising, the public is not protected from this abuse of trust in that vast sums of public money are already wasted on the prescribing of unnecessarily expensive drugs or inappropriate treatments in the name of clinical freedom. Outside the NHS the public are already legitimately exposed to commercial advertising by private hospitals and clinics with the GMC's blessing. Thus the ban on newspaper notices cannot be to protect the public from commercial pressures or the abuse of trust.

The use of newspapers to inform the public of the general medical services available to them in their community would increase the level of public awareness of these services with the effect that more people might decide to seek second opinions directly without being referred by their GP. In Britain there is a tradition that every one registers with a GP and that all referral is instigated by that GP. Although this practice is staunchly defended by the profession, to condemn direct self-referral absolutely is not only unrealistic but also not in the public's best interest. GPs practising in this system have immense control which is open to abuse, patients become regarded as possessions and often are, or feel, restricted from seeking further medical help.

In the correspondence columns of the British Medical Fournal (BMJ) (5) the practice of self-referral by the public was almost universally deplored and condemned by GPs. The only doctors accepting the practice spoke explicitly from the perspective of a parent or member of the public. Self-referral may offend against the profession's sense of etiquette but it is the public's right, as enshrined in the BMA's code of ethics, as the fundamental principle of free choice: ('A person is free to choose the doctor from whom he wishes to obtain medical advice' (6)). It is in fact the public's safety-net.

A possible argument against encouraging an increase in direct self-referral is that the doctor giving the second opinion will not have the regular GP's notes. This however is obviously not an overwhelming problem, as is plain from the fact that the profession accepts as normal a six-months delay in patients' notes catching up with them when they change doctors. This situation is however far from ideal and I suggest that instead of using this as an argument for restricting the public's freedom of choice it is a point in favour of patients having copies or summaries of their medical notes in their possession, a situation not actively encouraged by the profession (7).

Whilst the introduction of newspaper announcements may lead to some organisational changes and upset some doctors, the desire of the public for more information is surely more important, as the duty of a profession is to serve the public's interest in preference to its own. In response to the Government's discussion document Primary Health Care: An Agenda for Discussion (8) and after an eightmonth consultation period taking evidence from 73 organisations and including comments from nearly 250 bodies representing consumer, voluntary or professional organisations, the government concluded that 'more information for consumers to enable them to choose the doctor who best serves their needs' is needed (9). As well as the government's survey a report published in March 1988 of a survey carried out after the introduction of the new GMC guidelines, showed 
that for 216 patients who had recently changed doctors before January 1988, there was a lack of information available with eighty-six per cent wanting more general information on which to base their choice of GP (10).

People want easy access to information about the general medical services available to them in their locality. The GMC has agreed on the factual content of acceptable information (as referred to above), but restrict access to it. It seems reasonable to consider that newspaper notices are the most efficient and comprehensive means of distributing that information. Once access has been achieved additional avenues of distribution may be considered superfluous. This could be said of radio and TV commercials. The profession has always been aware that the level of promotion can be controlled not only by the content of the information but also by detail, such as the site and size of notices, heaviness of type etc and this principle of some control of presentation need not be abandoned. However, I am uneasy about the lengths to which both the GMC and the BMA are prepared to go in order to obstruct the public's access to this information, which suggests that the profession cannot be trusted to safeguard the public interest, in preference to its own, on this matter. The responsibility for regulating the profession on these matters may best be given to some other authority.

In spite of this need for more information the present guidelines are defended on the grounds of protecting public safety. People seeking medical help are seen as a particularly vulnerable group of individuals being susceptible to 'danger' from the raising of illusory hopes of cure (1). I will shortly address this fear of danger as it seems to be the only grounds on which it may be permissible to disregard a respect for the individual's wishes and autonomy, but first for the sake of completeness I must comment on the other two reasons considered by the GMC to justify the present restrictions concerning newspapers.

The first is that, 'the profession has long accepted the convention that doctors should refrain from selfpromotion'. This statement smacks of dogma. As previously stated, self-promotion in the form of puffery and blatant aggrandisement is to be deplored but there is no sharp distinction between information and soft self-promotion. To obey the guidelines to the letter would prohibit the dissemination of all information that in any way attracted potential patients. This would be contrary to the needs and spirit of today. The World Medical Association's Declaration of Lisbon (11) insists on the right of patients to choose their doctors freely, a decision, like informed consent, that requires information.

A second point is that it is feared that 'the doctor who is most successful at achieving publicity may not be the most appropriate for a patient to consult'. This is true but it is not an argument for denying the public easy access to information. It is equally true that a doctor chosen on a basis of no information may be equally inappropriate. It is perhaps an argument for guidelines to be drawn up as to what is considered excessive publicity. I would suggest that this would prohibit doctors' names from being connected with any material other than standard announcements. Those that presented TV or radio programmes or contributed to newspapers and magazines would have to use pseudonyms and leaks to the media about major new scientific breakthroughs in treatment or research would be prohibited from containing doctors' names and where they worked. Failure to introduce such guidelines would undermine the resolve to take the publicity point seriously.

The inappropriate doctor problem has recently been extended to include the third point, that of danger to the public. It is suggested that the consequences for the patient misled by advertising into choosing an inappropriate doctor may be 'disastrous' and that money alone would not compensate. This, it is considered, does not apply to accountants, solicitors, and other professionals and would be extremely rare even for dentistry, (12) all professions that are now permitted to advertise in newspapers.

It is obviously important that the public should not be misled and so it is worthwhile outlining the substantial protection the public already has under the British Code of Advertising (13) and the Institute of British Advertisers (IBA) Code of Advertising Standards and Practice (14).

As well as enjoining a general spirit of responsibility, fair play and the need for all advertisements to be legal, decent, honest and truthful, both codes impose particular restrictions with regard to health claims: 'No advertisement should employ words, phrases or illustrations which claim or imply the cure of any ailment, illness or disease, as distinct from the relief of symptoms.' This recognises the fact that people sometimes have unreasonable expectations.

Despite these safeguards the emotions triggered by the phrases 'inappropriate doctors', 'disastrous consequences', 'uncompensated by money', 'no danger from solicitors and rarely for dentistry', need to be addressed. I suggest that these provocative phrases have been emphasised deliberately to be alarmist and to present the dangers out of perspective. Indeed the rhetoric emanating from Tavistock Square in the public media overstates the danger to such an extent that it could undermine public confidence in the whole profession, contrary to the BMA's own ethical guidelines: the BMA of course disapproves of behaviour likely to bring the profession into disrepute.

In connection with public safety this seems particularly ill founded with reference to general medical services. GPs are the only group of doctors specifically trained to assess, manage or refer the patient who comes to them on a self-referral basis They are the accepted first point of contact with the medical services, they are expected to know their limitations and they have a duty to consider the overall well-being of their patients. In the UK GP training is compulsory, highly praised and the envy of many 
countries of the world and should be considered sufficient to safeguard the public.

This is not to say that the practice of medicine does not sometimes lead to tragic accidents and mistakes but rather that this danger is not likely to be increased significantly by newspaper announcements. In fact on the contrary, experience suggests that the benefits of a wider use of second opinions may well reduce the incidence of neglectful medical practice and iatrogenic disease.

Finally, with regard to the public danger argument it is worth noting that in their judgement (15) the two judges state that 'the vulnerability of sick patients to advertising and misleading advertisements - would only have force if unrestricted advertising were being proposed. If advertising of the limited form sought by the Applicant were permitted and strictly controlled, it is unlikely that the evils of commercial advertising for the medical profession and patients that they describe would occur'.

The GMC, by preventing the effective dissemination of information, is in effect denying the public access to it. This is an infringement of the liberty of the public and not just on the liberty of the doctors. J S Mill (16) when discussing the case for the restrictions on the sale of poisons to the public says 'where the object of the interference is to make it impossible or difficult to obtain a particular commodity, [or service] these interferences are objectionable, not as an infringement on the liberty of the producer or seller, but on the buyer'.

The GMC and BMA maintain excessively paternalistic stances in preventing public access to information on the grounds that the information may be harmful to the public. The profession has no grounds for such a stance. Paternalism is only considered appropriate when those you are protecting are children or insane, not when they are mature members of the British public. To treat the public as immature, let alone insane, is to insult them. Even if there are cases when doctors can be expected to make better technical medical decisions than their patients would make, and to advise patients accordingly (17) straightforward information about medical services is not of a technical nature and there is no justification for doctors withholding such information on the grounds of their superior medical expertise. To quote Mill again, when he discusses the grounds for preventing a man from walking over a dangerous bridge, Mill limits such action to when you have not had time to warn him first of that danger. 'When there is not a certainty, but only a danger of mischief, no one but the person himself can judge of the sufficiency of the motive which may prompt him to incur the risk' (16). To refer to Gillon again (18) when assessing our society, in which generally to participate in high-risk activities and high-risk occupations and in general taking responsibility for one's decisions, does not require a particularly high level of autonomy, he states that: 'It seems reasonable for doctors unless they are required by the democratic process to do otherwise, to accept that people possessing similarly minimal standards of autonomy should none the less have that autonomy respected in the context of medical care (in so far as such respect is compatible with respect for the autonomy of others)'. It is particularly inappropriate at a time when we are encouraging health promotion, prevention, self-help and healthy life-styles and a general sense of responsibility for our own well-being, to deprive the public of ready access to the information necessary for making an informed choice about their use of general medical services. It is an illogical restriction of their liberty and disrespectful of their autonomy.

I have confined the discussion of newspaper announcements to possible effects on NHS general practice and the public. There would also possibly be some other effects, the details of which I will not specifically address.

There is likely to be an increase in the number of private consultations for second opinions both by NHS GPs as well as totally private doctors. Some may see this as a retrograde step, others as a sign that the public are beginning to take their health seriously and are prepared to spend some extra money to care for it. I consider that this trend would be unlikely to undermine the NHS or the nation's commitment to the fundamental principle of a publicly funded health service.

The increased freedom for doctors to inform the public of the services they are prepared to offer might lead to an increase in innovative practices. Doctors who at present see no option other than leaving the medical profession for either private or professional reasons, may be prepared to offer their skills to the public on a part-time basis or to offer limited or special skills to complement those of their GP colleagues.

I consider that allowing easier access to factual, soft self-promotional information, about the availability of general medical services, by using newspaper announcements, should be ethically acceptable to the medical profession. This would be of benefit to the public, individual general practitioners and ultimately the medical profession.

\section{Acknowledgement}

I wish gratefully to acknowledge the help of Edgar Page whose discussion and comments on earlier drafts helped me clarify my argument.

Richard D Colman MB Bchir DRCOG MRCGP is an independent general practitioner in York who is also a student of moral philosophy. At present he is taking legal action against the GMC's restriction on the use of newspapers to disseminate practice information.

\section{References}

(1) General Medical Council. Professional conduct and discipline: fitness to practise. London: GMC, 1987.

(Continued on page 93) 
prescription off the pad with a flourish, a signal both of us recognised as the end of the consultation. He took it, got up and walked out.

After he left the room I brooded. Why do I feel more comfortable about treating as opposed to testing without full, informed consent?

What might happen in the intervening days? Would he be more agreeable to being tested on his return? I will have to wait and see.

Dr Simon Lundy MRCGP OPM (SA) is a General Practitioner and Editorial Associate of the Journal of Medical Ethics.

\section{(Continued from page 89)}

(2) British Medical Association. Annual report of council. London: BMA, 1987-88:31.

(3) British Medical Association. GMSC annual report 1986. London: BMA, 1986: appendix 11:31.

(4) This is my interpretation based on the evidence presented to the proceedings in the High Court of Justice, Queens Bench Division, Divisional Court. In the matter of the Medical Act 1983 - (Dr R D Colman v GMC) $1988 \mathrm{Jul}$.

(5) Correspondence. Self referral to consultants. British medical journal 1988; 296:861 and 1067.

(6) British Medical Association. The handbook of medical ethics. London: BMA, 1986:16.

(7) Kerries P. [editorial]. The practitioner $1989 \mathrm{Feb} 8$. In this editorial Dr Kerries says: 'The profession's negotiators successfully thwarted any move for patients to see their own medical records except those kept on computer file'.

(8) Government Green Paper, Discussion Document. Primary health care: an agenda for discussion. London: HMSO, 1986.

(9) Government White Paper. Promoting better health.
London: HMSO, 1987.

(10) Welford $R$. Why your patients may leave you. Medeconomics 1988; 9,5:33-37.

(11) See reference (7): 72 .

(12) Cogger N. Affidavit, High Court of Justice. Queen's Bench Division. In the matter of the Medical Act 1983. 1987 Jan 11.

(13) The British code of advertising practice. Brook House, Tormentor Place, London WCIE 7HN. Parts A, B and C.

(14) The IBA code of advertising standards and practice. 70 Brompton Rd, London SW3 1EY: IBA, 1987: Appendix 3: 359-360.

(15) Judgement. High Court of Justice, Queens Bench Division, Divisional Court. In the matter of the medical act 1983-(Dr R D Colman v GMC) 1988 Nov 25.

(16) Mill J S. On Liberty. London: J M Dent \& Sons Ltd, 1948: 151-152.

(17) Gillon R. Paternalism and medical ethics. British medical journal 1985; 290: 1971-1972.

(18) Gillon R. Where respect for autonomy is not the answer. British medical journal 1986; 292:48-49.

\section{News and notes}

\section{Research fellowships 1990-91}

Applications are invited for the Tennent Caledonian and Royal Bank of Scotland research fellowships for the academic session 1990-91.

The fellowships are intended primarily, though not exclusively, for philosophers and political theorists on study leave from their own universities or colleges. Appointment is normally for one term and the fellowship carries a travel allowance, accommodation in St Andrews and a room in the Department of Moral Philosophy, and access to word-processing facilities. Further details are available from the Director, Dr John Haldane, Centre for Philosophy and Public Affairs, University of St Andrews.

Applications, including a cv, a short statement of research intentions or plans, and an indication of the term during which the fellowship would be held should be submitted no later than 15 November 1989 (though early applications are welcome) to: The Director of Personnel Services, College Gate, University of St Andrews, North Street, St Andrews, Fife KY16 9AJ, Scotland, UK. 